\title{
¿IMAGINAR EL FUTURO? 2033 Y EL RESURGIMIENTO DEL CINE MEXICANO DE CIENCIA FICCIÓN
}

\author{
POR \\ Miguel García \\ University of California, Davis
}

Hablar del cine mexicano de ciencia ficción evoca inevitablemente dos imaginarios distintos, uno proveniente de Hollywood y el otro de temáticas e iconografía nacionales. Pese a sus diferencias, ambos imaginarios se entrecruzaron hasta integrar un género que, durante su mayor auge -las décadas de los sesenta y setenta-, alcanzó una popularidad equiparable en términos de taquilla al cine de la "Época de oro". Pero el éxito del cine mexicano de ciencia ficción no se circunscribió al espacio de las salas de proyección ni al territorio nacional, sino que circuló ampliamente en otros países, sobre todo en los Estados Unidos y en Europa, donde adquirió cierto estatus de cine de culto (Wilt 11). La televisión mantuvo vigente el imaginario de la ciencia ficción de este periodo y hoy, con la aparición de nuevos medios (el cable, la internet y el DVD), este cine ha encontrado nuevas vías de difusión. Curiosamente, la notoriedad del género no se tradujo en un interés por parte de la crítica, la cual desdeñó la ciencia ficción mexicana por considerarla una insípida y burda imitación de lo producido en Hollywood: un mero producto comercial que carecía del brillo del cine de oro.

La infravaloración del cine mexicano de ciencia ficción sorprende aún más si se toma en cuenta que México ha sido el mayor productor de cine de este género en América Latina, con más de un centenar de largometrajes (Paz 84). Este factor por sí mismo vuelve relevante el estudio del cine de ciencia ficción mexicano, en tanto demuestra que formó parte importante de la consolidación de la industria cinematográfica en el país. De igual manera, dado que la ciencia ficción ha sido uno de los pocos géneros que han discutido y representado explícitamente conceptos relacionados a la tecnología y la ciencia, así como la relación de éstas con el Estado, su estudio puede aportar claves para dos problemáticas recurrentes en el campo de la cultura mexicana poco exploradas hasta el momento: 1) ¿Cómo ha respondido el cine ante los procesos de tecnificación de México, vistos como símbolos del proyecto modernizador nacional, el cual empieza en los años cuarenta con el "milagro mexicano" y que prosigue hoy tras la implementación del modelo neoliberal desde la firma del Tratado de Libre Comercio (TLC) en 1994; 2) 
¿Cómo influye en el cine mexicano la adopción, imitación y reapropiación de modelos fílmicos extranjeros, en especial aquellos asociados con la tecnología?

El abordaje a estas problemáticas se hará aquí a través de un análisis de la película 2033 (2009), dirigida por Francisco Laresgoiti. Este filme, como la mayoría de los nuevos ejemplos del género, construye un mundo futurista y distópico en donde un gobierno tecnócrata somete a la población mediante un autoritarismo represivo que emplea la tecnología como un dispositivo de control. Dicha visión negativa de la tecnificación responde a la preocupante integración de México al capitalismo global, proceso que en ocasiones ha creado levantamientos hostiles para combatirlo. Si bien este filme critica ciertos aspectos del modelo neoliberal, se cuestionarán los alcances políticos de la utilización del género de la ciencia ficción, un tipo de cine íntimamente ligado a Hollywood, sobre todo en cuestiones de comercialización y distribución. Sin embargo, antes de iniciar el trabajo será necesario introducir dos digresiones. La primera se dedicará a proveer una definición del cine de ciencia ficción, mientras que la segunda ofrecerá una visión panorámica de este cine en México, digresión relevante puesto que en general el cine de ciencia ficción en español no ha contado con una narrativa que lo sitúe históricamente.

\section{HACIA UNA DEFINICIÓN RELACIONAL DE LA CIENCIA FICCIÓN}

Debido a que frecuentemente se tiende a definir la ciencia ficción a partir de presupuestos teóricos formalistas, conviene aclarar que se entiende aquí la ciencia ficción no como un género reducible a convenciones estilísticas, icónicas, o temáticas fijas. El cine de ciencia ficción es un género fluctuante, en constante redefinición, que incorpora y desecha elementos sin trazar necesariamente programas estéticos, políticos o ideológicos explícitos; por lo tanto, acotar los atributos de la ciencia ficción bajo una perspectiva interfílmica (es decir, tomando en cuenta sólo lo que sucede dentro de la película, leyéndola como un texto), resulta insuficiente. Así, una definición de la ciencia ficción como la esbozada por Vivian Sobchack, a pesar de su valor e influencia en el estudio del género muestra sus limitaciones:

The SF film is a film genre which emphasizes actual, extrapolative, or speculative science and the empirical method, interacting in a social context with the lesser emphasized, but still present, transcendentalism of magic and religion, in an attempt to reconcile man with the unknown. (63)

Sobchack se decanta por el lado formal y al hacerlo, como muchos otros críticos, lleva a cabo un procedimiento que aunque pudiera ser productivo en el ámbito literario, en el cinematográfico se vuelve problemático, pues deja a un lado precisamente 
aquellas características más sobresalientes del medio audiovisual. Como todo género cinematográfico, la ciencia ficción se construye en parte en base a factores extrafílmicos: comunidades interpretativas (críticos especializados, académicos, espectadores), campañas publicitarias (afiches, anuncios, tráilers), circuitos de circulación (festivales, internet, televisión), y redes de referencias a obras que se asocian con un canon. Así, una definición no circunscrita al plano formal necesariamente requiere incorporar todos estos elementos que, como consecuencia, posibilitan describir la ciencia ficción como un género dúctil, un ensamblaje de elementos abierto además a flujos intergenéricos, de tal forma que una película puede pertenecer a uno o incluso a varios géneros simultáneamente. ${ }^{1}$

El partir de esta redefinición permite acercarse a la ciencia ficción mexicana desde una perspectiva más compleja, sin pasar por alto el contenido de una película, pero sin privilegiarlo. A continuación se tratará precisamente de hacer visibles estos ensamblajes múltiples a través de una contextualización histórica del cine mexicano de ciencia ficción, mencionando algunos temas y figuras clave para entender este cine, y resaltando las conexiones con el cine de Hollywood.

UN VISTAZO AL PASADO: BREVE RECUENTO DEL CINE MEXICANO DE CIENCIA FICCIÓN DESDE SUS INICIOS HASTA HOY

Según la filmografía establecida por Itala Schmelz en el único libro completamente dedicado al cine de ciencia ficción en México, El futuro más acá: cine mexicano de ciencia ficción, la primera cinta de ciencia ficción es El misterio del rostro pálido, estrenada en 1935 (242). Aunque se exhibieron otras películas similares durante los años treinta y principios de los cuarenta, este cine no se consolidaría sino hasta finales de la década del cincuenta, al mismo tiempo que el cine de la "época dorada" perdía su brillo.

Si el cine dorado había forjado una identidad colectiva, un México imaginado, que había conseguido prestigio internacional a través de sus películas (Peredo 467), el cine que tomó su lugar fue visto como un espectáculo barato para las masas. En efecto, la industria mexicana redujo los costos de sus producciones con el fin de competir ya no en calidad, sino en número, con Hollywood, industria que tras la Segunda Guerra Mundial reapareció fortalecida y con ansias de reconquistar el terreno perdido durante el periodo bélico. Las clases medias y altas dejaron de apoyar al cine mexicano, pues con el impulso modernizador del "milagro mexicano" resultaba más cosmopolita y sofisticado apoyar al cine extranjero (léase: europeo y estadounidense), que el nacional. Surgieron en México los "churros": películas de bajos valores de producción, con malas actuaciones y tramas que integraban temáticas extraídas de las películas estadounidenses

Sigo aquí algunos de los postulados de la "teoría de los géneros" (genre theory), tal como la emplea Keith Johnston a la ciencia ficción en su reciente Science Fiction Film: A Critical Introduction. 
de moda, adaptadas al contexto mexicano a través de la incorporación de elementos nacionales, y orientadas hacia un público "semianalfabeto" (Fernández 136).

Sin embargo es justamente gracias a los churros que la ciencia ficción mexicana se desenvolvió, mezclando elementos representativos del cine de ciencia ficción hollywoodense con asuntos y personajes arquetípicos del cine nacional. De ahí que coexistan en la ciencia ficción mexicana platillos voladores, máquinas sofisticadas, científicos locos, rumberas, comediantes y luchadores. Estos últimos, señala Schmelz, protagonizaron el $30 \%$ de las películas del género (262); su indiscutible figura central es El Santo, quien estelarizó películas como Santo contra el cerebro del mal (1958), Santo contra los asesinos de otros mundos (1971), y Santo contra el Doctor Muerte (1973). Los argumentos siguen, típicamente, la siguiente fórmula: los primeros minutos muestran la aparición, en la Ciudad de México, de una amenaza (en la forma de una invasión extraterrestre, o de un monstruo creado por un científico); las autoridades convocan a El Santo, héroe de los cuadriláteros y agente encubierto, para que les ayude; finalmente, El Santo derrota al mal, sin descuidar su faceta como luchador profesional. Otras películas mezclan la ciencia ficción con la comedia, y se puede afirmar que prácticamente todos los comediantes reconocidos del momento (Resortes, Clavillazo, Viruta y Capulina, Piporro) participaron en alguna película de este tipo. ${ }^{2}$

¿Cómo competir con Hollywood en el rubro de la ciencia ficción, si durante esta época el imperativo de las casas productoras mexicanas era recortar gastos? Con frecuencia la estrategia fue simplemente hacer rendir el presupuesto, aun a costa de evidenciar "El acabado en cartón, el set reciclado, los hilos nailon que elevan las naves espaciales, el cierre en el disfraz del monstruo ..." (Schmelz 18). Pero muchas otras veces, las películas mexicanas emplearon un "efecto legitimador", en otras palabras, un recurso que apela deliberadamente a elementos que los espectadores y otros miembros de las comunidades interpretativas reconocen como pertenecientes a un género. Este efecto legitimador, el cual en ocasiones es la única marca que permite clasificar a estas películas como parte de la ciencia ficción, consistió en apropiarse legal o ilegalmente de secuencias tomadas de películas estadounidenses del género; dichas tomas luego se utilizaban en aquellos momentos fílmicos que requerían la presencia de naves espaciales, cohetes, extraterrestres y demás parafernalia, debido a que resultaba más barato pagar o plagiar metraje ya filmado que producirlo en México (78). ${ }^{3}$

2 La enumeración del algunos títulos aporta pistas sobre las temáticas de los filmes: La nave de los monstruos (1959), El conquistador de la Luna (1960), El planeta de las mujeres invasoras (1965).

3 A lo largo del volumen editado por Schmelz se nombran muchos de estos casos de plagio o préstamo. Por ejemplo, Miguel Ángel Fernández indica que varias secuencias de Destination Moon (1950) fueron utilizadas en al menos dos películas mexicanas, y que además se empleó material visual de esa misma película para crear carteles promocionales para un filme mexicano (140). 
Algunos críticos leen las deficiencias y carencias técnicas del cine mexicano de ciencia ficción como una extensión de las actitudes populares acerca de la tecnología y la modernidad. Para Schmelz, por ejemplo, "[1] a parafernalia es la materialización en la pantalla del desinterés por la ciencia [...]" (78). Por su parte, Naief Yehya indica que si bien la ciencia ficción reproducía el discurso modernizante proveniente del gobierno, al mismo tiempo lo travestía: "Las fantasías tecnológicas se vuelven entonces un vehículo para mofarse de la solemnidad científica, para crear una complicidad en la ignorancia entre los cómicos y un público sin interés por entender los inventos y descubrimientos que están cambiando al mundo" (72). El cine de ciencia ficción de esta época desplazó al terreno de la ficción los debates que se daban en la esfera pública, en un momento de urbanización acelerada que no necesariamente resultó en la integración de la nación al modelo industrial y capitalista que se erigió tras la Segunda Guerra Mundial.

Este cine disminuiría su presencia en las salas de cine a mediados de los años setenta, pero el imaginario creado durante alrededor de veinte años no se diluiría del todo, debido en gran parte a la circulación que estas películas adquirieron gracias a la televisión. Salvo contadas excepciones, los filmes de ciencia ficción que se produjeron en los ochenta y noventa se inscribieron en la línea de los churros, incapaces de competir contra el poderío de Hollywood, que en esos años estrenó Star Wars (1977), Terminator (1984), The Matrix (1998), entre otros. ${ }^{4}$ No obstante, en la última década han aparecido varias películas mexicanas que se autoproclaman representantes de la ciencia ficción y se proyectan en festivales especializados del género, pero que se alejan deliberadamente del modelo popularizado durante la época de los churros. La nueva ciencia ficción, sin embargo, retrata aún las tensiones entre los proyectos modernizadores y la tecnología, así como la compleja relación entre Hollywood y el cine nacional.

\section{EL MOMENTO ACTUAL: EL CINE DE CIENCIA FICCIÓN EN EL NEOLIBERALISMO}

La implementación del modelo neoliberal en México, a partir de finales de la década de los ochentas, repercutió no sólo en el plano económico, sino prácticamente en todos los ámbitos, incluidos el tecnológico y el cultural. El Tratado de Libre Comercio, ${ }^{5}$ símbolo de la apertura al capital transnacional, resignificó el cine mexicano, transformándolo en un producto de entretenimiento; según Rosas Mantecón "los negociadores mexicanos permitieron que la industria cinematográfica quedara dentro del sector de comunicaciones

4 En palabras de Sobchack, el cine estadounidense de ciencia ficción experimentó un "renacimiento" tras el lanzamiento, en 1977, de Star Wars y Close Encounters of the Third Kind (226). Este nuevo momento de la ciencia ficción estadounidense se dio en paralelo a (o a causa de) la creación de nuevas tecnologías electrónicas, como la computadora y los juegos de video (224), innovaciones cuyo uso no se extendería en México de la misma forma que en el país del norte.

5 O NAFTA, por sus siglas en inglés (North American Free Trade Agreement). 
no como un bien cultural, sino inmerso en el subsector de servicios de esparcimiento" (287). Bajo el avatar neoliberal, el capital privado percibió en el cine mexicano el potencial para un proyecto rentable económicamente, siempre y cuando se re-dirigiera hacia las clases medias y altas (MacLaird 47). A partir de ese momento se empieza a desarrollar una estética hecha a la medida de las clases pudientes, que refleja sus gustos e ideologías. De esta forma, géneros que anteriormente habían sido rechazados por la industria mexicana, como la comedia romántica o el cine "alternativo", se vuelven parte del mainstream, mientras que los tipos de cine más populares desaparecen (Sánchez Prado).

A la luz de estas transformaciones no resulta sorpresivo el resurgimiento de la ciencia ficción en el nuevo cine, ni asombra que se reconstituya en clave hollywoodense: el churro no es ya un cine rentable o apropiado para los nuevos espectadores, por lo tanto hay que buscar enlazarse al paradigma de ciencia ficción que el público actual reconoce -nuevamente, el estadounidense-. Desde luego, el problema central radica en la dificultad de emular al cine hollywoodense de ciencia ficción actual pues, como Keith Johnston demuestra, éste se ha destacado en los últimos años por el uso cada vez más profuso de los efectos especiales (107), mientras que en México son pocas las producciones que los emplean. ¿Cómo producir ciencia ficción que trate sobre las nuevas tecnologías, que sea agradable visualmente, y que no reproduzca la estética del churro? Este ha sido el dilema de la ciencia ficción mexicana, que hasta el momento ha encontrado tres maneras para intentar resolverlo. La primera ha consistido en adoptar y transformar, en vez de rechazar, algunos elementos del churro, como lo hace Polvo de Ángel al usar luchadores y situaciones cómicas que recuerdan las películas de los sesenta y setenta. ${ }^{6}$ La segunda forma ha sido optar por la coproducción (Sleep Dealer, México/EE.UU.; Polvo de Ángel, México/Colombia), lo cual ha permitido dedicar más recursos a la etapa de posproducción. Finalmente, la tercera estrategia, la más empleada, radica en producir una serie de efectos legitimadores mediante la referencia intertextual explícita a obras conocidas de la ciencia ficción hollywoodense, la puesta en escena de efectos especiales, ${ }^{7}$ y la selección de temas serios, como los problemas sociales provocados por las desigualdades económicas, la destrucción del planeta por la acción humana, la violencia de Estado, etc.

\footnotetext{
$6 \mathrm{Al}$ mismo tiempo esta película marca su distancia con los churros al proponer una estética que incorpora animaciones semejantes a las historietas de los superhéroes de Marvel y DC Comics.

7 Los avances tecnológicos permiten hoy que producciones con presupuestos mucho menores a los de las grandes compañías tengan acceso a efectos especiales de buena calidad. Persiste, sin embargo, una desigualdad en cuanto a los resultados, ya que un filme con más inversión económica usualmente puede emplear efectos mejor realizados. César Huerta apunta que mientras que la película Sector 9, apoyada por Peter Jackson aunque no asociada con Hollywood, costó alrededor de 30 millones de dólares, 2033 utilizó un presupuesto de 25 millones de pesos, es decir, una cantidad menor a los 2 millones de dólares (“¿El futuro de la Ciudad de México?).
} 
El corpus del género durante la nueva etapa lo integran cerca de una decena de películas, ${ }^{8}$ que aunque contienen propuestas visuales y temáticas diferentes, comparten un rasgo en común: todas utilizan un recurso habitual de la ciencia ficción conocido como "extrapolación", el cual Gary K. Wolfe define como "the technique of basing imaginary worlds or situations on existing ones through cognitive or rational means"(33). Específicamente, en estas películas la extrapolación se da a través de la representación futurista y distópica de espacios identificables de México y América Latina. La última muerte, por ejemplo, muestra un espacio dominado por las tecnologías digitales y el control de la población mediante un banco mundial de información. En este lugar la pena de muerte y la clonación se conjugan para ocasionar dilemas éticos y morales en los protagonistas. En De día de noche un gobierno totalitario decide enfrentar el problema de la sobrepoblación convirtiendo a la mitad de los habitantes en ciudadanos nocturnos y a la otra mitad en diurnos. El conflicto se da cuando los personajes trasgreden este nuevo orden.

¿Por qué eligen estas nueva películas el tropo distópico? Una de las razones es sin duda aprovechar la creación de una distopía para cuestionar oblicuamente el presente. Sin embargo, la representación futurista también responde a factores comerciales, dado que este tipo de películas generalmente apela a una espectacularidad explícitamente inscrita en el diseño y los efectos especiales (ver la reciente The Hunger Games, por ejemplo) y que el público suele esperar y hasta exigir. Dentro de este nuevo paradigma de la ciencia ficción mexicana, 2033 es una película representativa en tanto sigue varios de los patrones aquí delineados, pero que a la vez propone otras rutas para el género en el país.

\section{3: LA CIENCIA FICCIÓN VIENE DE AFUERA}

Desde un inicio 2033 se intentó codificar como un caso de ciencia ficción mexicana, incluso antes de que alguien la viera. En "Las cucarachas invaden el D.F. en la cinta 2033", publicado en el año 2008, apenas una semana después de terminado el rodaje, el articulista César Huerta describe el ambiente futurista que se planea construir en posproducción y que incluirá "salas de criogenia", edificios gigantes y la presencia de cucarachas ruidosas. El afiche promocional presentaba los perfiles de los personajes principales en la parte superior, mientras que la parte central estaba dominada por un enorme rascacielos y un arco aun más grande que el edificio. La página web oficial, por su parte, destacaba el paso del filme por varios festivales de fantasía y de ciencia ficción-Fastastikfilmfestival, Suecia; S+F, Italia; Sci-fi London, Inglaterra- antes de

8 Polvo de Ángel (2008), Sleep Dealer (2008), De dia y de noche (2009), 2033 (2009), Depositarios (2010), Seres Génesis (2010) y La última muerte (2011). 
su estreno en México. Si bien las reseñas que se publicaron luego del debut fueron en general negativas, ninguna le negó a 2033 el estatus de filme de ciencia ficción. En este sentido, el filme de Francisco Laresgoiti logró uno de sus objetivos primordiales: insertarse en los circuitos de distribución de la ciencia ficción e inscribirse como representante mexicano del género. Pese al rotundo fracaso en taquilla, 2033 acaparó los reflectores por un momento, al ocupar un nicho que había permanecido vacío durante décadas. ${ }^{9}$ De ahí que cuando finalmente se editó en DVD, la portada mostrara orgullosamente la leyenda: "Primera película mexicana de ciencia ficción desde hace 25 años". Al trazar el camino de 2033 se puede claramente ver que su catalogación como ciencia ficción obedeció a criterios externos en primer lugar, y que las partes visuales y temáticas parecen haber jugado solamente un papel determinante en cuanto al juicio de la obra (es decir, para calificarla de buena o mala película de ciencia ficción). Por lo tanto, y volviendo a una de las reflexiones del comienzo de este artículo, pretender limitar el estudio de la ciencia ficción a aspectos de contenido y forma no daría cuenta de la manera en que un filme como 2033 interacciona con la industria cinematográfica mexicana y global.

La película de Laresgoiti, cuya historia se desarrolla en el año 2033, presenta un México gobernado por un régimen militar que ocupó el poder tras el caos posterior a las elecciones del 2012. La autoridad absoluta recae en el líder supremo PEC y en el General Jamaro, su mano derecha. Para controlar a la población, el régimen se alía con el Dr. Stam, un científico de la industria farmacéutica quien ha desarrollado el Pactia, una bebida que torna dóciles a los habitantes. Como medidas adicionales para imponer su autoridad, PEC ha prohibido la religión y ha puesto en cápsulas de "criopausa" (animación suspendida) a los intelectuales, políticos y científicos de oposición. Villaparaíso, nuevo nombre de la antigua Ciudad de México, se divide ahora en dos sectores claramente delimitados. Mientras que en el centro habitan los trabajadores controlados por el Pactia y la élite gobernante, en las afueras de la urbe viven los pobres, que son perseguidos y cazados por deporte. El conflicto del filme gira alrededor de Pablo, un joven perteneciente al grupo privilegiado que debe elegir entre permanecer en su posición de autoridad, o unirse al grupo rebelde que pretende derrocar al régimen y traer de vuelta la religión.

Cabe mencionar que en diversas entrevistas, Laresgoiti y su guionista Jordi Mariscal declararon que debajo del argumento de 2033 subyace una re-narración del conflicto de la Guerra Cristera, un enfrentamiento entre el Estado y la Iglesia Católica que ocurrió durante los años de 1926-1929 (Caballero). ${ }^{10}$ De hecho, el título inicial de

9 Quizás de haber alcanzado el éxito comercial se habría cumplido la ambición inicial del director, quien planeaba realizar una trilogía en la cual 2033 ocupaba la parte intermedia (Huerta, "Más de 100 mil" s/p).

${ }^{10}$ A riesgo de simplificar, la Guerra Cristera (también llamada Cristiada) sucedió a causa de una ley, promulgada por el gobierno, que limitó severamente la libertad de culto y afecto sobre todo a los católicos (ver Meyer para un recuento detallado). 
la película era $V C R$, una alusión al grito de batalla de los cristeros (¡Viva Cristo Rey!). El nombre del dictador PEC alude a Plutarco Elías Calles, el presidente de México durante el conflicto y quien es señalado como el responsable directo del problema; asimismo, los personajes principales y parte de la trama reactualizan figuras y eventos de la Guerra Cristera. Aunque estas conexiones entre la película y la historia del país ayudan a entender cuestiones como la elección de la figura del dictador -figura que en el cine mexicano contemporáneo es reemplazada por la del presidente autoritario-, en realidad los puntos de contacto son más bien vagos y nunca explícitos. Esto quiere decir que los paralelismos entre la realidad y la ficción son demasiado tenues y por lo tanto no serán objeto de este análisis.

2033 se organiza alrededor de oposiciones dialécticas (ricos/pobres, modernidad/ primitivismo, opresores/libertadores, ateos/creyentes, etc.) que se ven reflejadas visualmente a través de la construcción de los dos espacios principales. Por un lado, el ambiente tecnificado en el que se mueve la élite se compone por colores brillantes y fríos (blancos, azules, grises), y escenarios y locaciones que enfatizan líneas rectas, que en conjunto crean un tono de asepsia y orden. En contraste, el mundo de los pobres se constituye en base a colores opacos y calientes (cafés, amarillos, rojos), que funcionan para mostrar un espacio menos artificial, donde la comunidad aún es posible.

Pero, obviamente, la estética y el contenido de 2033 no se producen en un vacío; al contrario, un espectador habitual o incluso casual de películas de ciencia ficción puede reconocer fácilmente varias intertextualidades con clásicos de la ciencia ficción. Entre las "citas" más evidentes están las referencias a THX 1138, 1984, Farenheit 451, Matrix, cintas que tienen en común la representación de sociedades controladas por un poder represivo. Al recurrir a estas menciones, 2033 busca autolegitimarse inscribiéndose, gracias al seguimiento de los códigos hollywoodenses, dentro de la ciencia ficción "auténtica". La deuda visual también se percibe a través del empleo de efectos especiales, particularmente los generados por computadora y que aparecen en momentos estratégicos de la película. ${ }^{11}$

Así como se pueden apreciar ya desde la producción material de la película algunas de las contradicciones de intentar asociarse a un género juzgado muchas veces a partir de su visualidad, el contenido también presenta un dilema, ya que al tratar de adaptar temáticas de la ciencia ficción estadounidense al contexto mexicano se manifiestan las paradojas de filmar en un género como este. Si las películas de ciencia ficción de los sesentas apoyaban el discurso modernizador del Estado, urbanista y tecnológico, el

${ }^{11}$ Los primeros veinte minutos de la película establecen el ambiente futurista, mostrando pantallas táctiles, robots de limpieza, edificios de arquitectura abstracta, escáneres oculares y demás gadgets. Pasados estos minutos, los efectos especiales se colocan al fondo, reapareciendo ocasionalmente sobre todo en las escenas de acción. 
nuevo cine de ciencia ficción critica fuertemente la capacidad del gobierno para usar con responsabilidad las nuevas tecnologías, a la vez que interroga de dónde viene realmente el capital y la innovación científica que se intenta promover. ${ }^{12}$

En la mayoría de estas películas son las compañías transnacionales las que poseen en verdad el control. Aunque el dictador PEC puede asemejarse a los ambiciosos caudillos que gobernaban con mano de hierro al país después de la Revolución mexicana, en 2033 el verdadero dominio recae en el Dr. Stam, el creador del Pactia. Este científico actúa dentro de la película como un mercenario, dispuesto a vender sus conocimientos a quien le convenga, por eso sabe que PEC accederá a cualquier petición con tal de mantener a la población bajo control con el Pactia. En una de las primeras escenas, luego de que un pordiosero logra llegar al perímetro de la fábrica donde se procesa el Pactia, el Dr. Stam le advierte al General Jamaro: "Tus agentes no están funcionando. Si entra un fanático más a mis laboratorios, me voy, con todo y Tecpanol [sustancia activa del Pactia], hay muchos gobiernos interesados..." Después, cerca del final, cuando estalla la rebelión contra el régimen, Stam amenaza nuevamente: "No me obligues a buscar alternativas en Inglaterra o en Israel". En otra escena, un grupo de empresarios se reúne con el General Jamaro para discutir las pérdidas provocadas luego de que la rebelión se manifiesta:

Empresario 1: General, ¿qué está pasando? Me atacaron quince máquinas de depósitos. Empresario 2: Me boicotearon dos almacenes de energía eólica.

Empresario 3: A mí, me destruyeron dos antenas de comunicaciones. (alza la voz) No estamos siendo correspondidos.

Ante la oleada de recriminaciones, el General Jamaro se levanta furioso de la mesa y les contesta frustrado: “¿Saben ustedes lo que es un trabajo en equipo? En este régimen ustedes se llevan la tajada más grande y jugosa del papel, pero algunos no están haciendo bien su trabajo ...". Si el Pactia simboliza el pacto entre el gobierno y el capital privado, el diálogo anterior refleja la asimetría de dicho pacto. En última instancia, el régimen tiene que acceder a las demandas de Stam y los empresarios, reenforzando con ello el papel subordinado de los "gobernantes".

La unión del dictador y el científico puede leerse también simbólicamente, pues más que personajes, estas figuras funcionan como arquetipos, entes unidimensionales construidos a partir de características predeterminadas; de ahí que ambos personajes ostenten los títulos que los enmarcan en una profesión, y nunca se les vea llevar otra ropa que no sea la que los describe: el General Jamaro y su uniforme militar, el Dr. Stam y su bata blanca. Bajo esta lectura simbólica, el General representaría a los dictadores

12 Para complicar esta situación, 2033 (y la mayoría de las películas de Ciencia ficción recientes) contó con el financiamiento parcial del gobierno, así como con la colaboración del capital privado. 
y caudillos latinoamericanos que gobernaron durante buena parte del siglo XX, y a los cuales regularmente se asocia con la implementación de políticas neoliberales (en Chile, Argentina y Brasil, por ejemplo). Stam, con su apellido decididamente extranjero, representaría el poder de las compañías transnacionales, altamente móviles e interesadas más en vender servicios que en manufacturar productos.

La combinación de un régimen interesado en mantener sometida a la población y la lógica del corporativismo global que se basa en la fluidez podría parecer a primera vista contradictoria. Sin embargo, Eugene Thacker y Alexander Galloway en The Exploit muestran, partiendo del análisis de la biopolítica de Foucault y de los postulados sobre las "sociedades de control" de Deleuze, cómo ambas lógicas interactúan y generan, en la etapa del capitalismo actual, un nuevo tipo de organización a través de redes (que pueden ser informáticas o biológicas). Para Thacker y Galloway, la nueva biopolítica de redes incluye, entre otras cosas: un cambio en el objeto de control, pues ya no se controla al sujeto como ente civil o cuerpo individual, sino a la población como especie biológica; el uso de tecnologías informáticas para establecer normas y jerarquías; un modelo de soberanía que no se interesa en decidir quién muere, sino en controlar, optimizar y regular a quienes viven; y una preocupación por la seguridad al mismo tiempo que se fomenta la creación de nuevas redes (sociales, económicas, políticas, etc.) (76).

En 2033, la biopolítica de redes se presenta a través de las nuevas formas de control de la población. Los habitantes de Villaparaíso no son ni esclavos ni prisioneros, pero el Pactia los hace "trabajar como robots", es decir, los deshumaniza. La ausencia de religión, en el contexto de la película, también funciona como un elemento que reduce a los ciudadanos a meros obreros sin un propósito trascendental. De igual manera, el consumo voluntario de drogas por parte de la élite joven, juniors prepotentes que asisten a un bar muy similar al de La naranja mecánica de Kubrick. Ese uso se presenta como el peor de los vicios, pues implica una internalización de las reglas del régimen. También, como se mencionó anteriormente, a los que rechazan el régimen no se les extermina, como sí sucedió durante las dictaduras latinoamericanas, sino que aquí se les reprograma, por medio de las computadoras, para que sirvan a PEC. La tecnología, si bien parece constituir parte fundamental de la vida de la ciudad, permanece fundamentalmente en las manos de la élite, que la usa para monitorear las actividades de la población y también para mantener a salvo la zona central de cualquier contacto con los pobres.

Pero así como actúan estas funciones de la biopolítica de redes para reprimir, también existen maneras para usar las redes en "prácticas oposicionales" (Thacker y Galloway 98), esto es, prácticas que valiéndose de las redes se enfrentan contra el poder. En 2033, la práctica oposicional más importante es la que se da mediante la emergencia de grupos rebeldes en distintas zonas del país, que se caracterizan por su rechazo al Pactia y su adhesión a una forma de religión que ellos entienden como una creencia libertaria, dado que regresa el control del cuerpo a los individuos y les 
permite forjar vínculos intrapersonales más profundos, ajenos al ámbito laboral. Estos grupos se organizan como redes descentralizadas que se mueven independientemente y que comparten tan sólo el anhelo de derrocar a PEC y ser tratados como "personas y no como simples números". La película focaliza en una de estas agrupaciones que tiene como misión integrar a la rebelión a Pablo, el protegido del General Jamaro, pero que en realidad es hijo de uno de los líderes de la guerrilla que fue capturado y puesto en una de las salas de criopausa. La "reprogramación" de Pablo se da gradualmente, gracias a la revelación de la verdad de su pasado. Pablo colabora después en una labor de infiltración en las salas de criopausa donde mantienen a su padre, a quien salvan mediante el uso de aparatos de hackeo y a las claves de acceso de Pablo. Como se ve, las estrategias de redes no son exclusivas de los grupos opresores, sino también de los oprimidos. Así se entiende por qué la misión mayor de la rebelión no es destruir la fábrica donde se produce el Pactia, sino desarrollar un antídoto y distribuirlo por el mismo medio donde circula la bebida del gobierno.

En esta película, como en otras muestras de ficción distópica, la tecnología posee un carácter neutro, pues puede ser usada de acuerdo a los intereses de diversos grupos. Aún así, el fracaso del grupo donde participa Pablo, tras la ejecución de uno de los cabecillas del movimiento y la siguiente huida de los sobrevivientes hacia la sierra, exhibe una problemática que no siempre trata el cine de Hollywood: no basta tener acceso a la tecnología para intervenir exitosamente y cambiar el sistema, pues el sistema de represión elimina, neutraliza, reconfigura y hasta se apropia de los métodos que se usan para combatirlo. A diferencia de las películas estadounidenses típicas, el héroe de 2033 no vence, no se restablece la religión ni se suprime al Pactia, solamente aparece como última esperanza la noticia de que existen otros focos de resistencia en algún lugar de la sierra que Pablo debe encontrar para reorganizar otra sublevación en el futuro. La alianza de PEC y el Dr. Stam se reafirma al final, aunque saben que por no haber exterminado completamente la rebelión tendrán que enfrentarse de nuevo.

Mientras que Galloway y Thacker describen la biopolítica de redes actual que observan a través de las políticas de Estados Unidos, en 2033 dicho proceso se muestra como parte de un futuro que aún no llega, y que por lo tanto puede prevenirse. La insistencia en denunciar los excesos de la clase gobernante, que sin embargo subroga su poder a los representantes del capital global, expone una severa crítica al presente, que en México y América Latina obliga a repensar el papel no sólo de las cúpulas de poder, sino también de aquellos más afectados por este tipo de políticas, como los pobres. En el contexto mexicano, el movimiento guerrillero en el que participa Pablo recuerda inmediatamente al del EZLN (Ejército Zapatista de Liberación Nacional), que se alzó justamente el día en que entró en vigor el Tratado de Libre Comercio con América del Norte (TLCAN), y que se valió del internet como medio para difundir su mensaje. Significativamente, en la coproducción México/USA Sleep Dealer también se 
aprecia un movimiento que se describe en términos similares al EZLN. La insurrección se autonombra EMLA (Ejército Maya de Liberación del Agua) y sus miembros portan pasamontañas y se comunican por la Red, como los zapatistas. ${ }^{13}$

CienCIA FiCCIÓN ACTUAL: ¿MODA PASAJERA O CONSOLIDACIÓN?

Aunque en ocasiones la película cae en posicionamientos moralistas, sobre todo al proponer como solución viable la adhesión a una creencia religiosa -que veladamente se refiere al catolicismo-, sin cuestionar el control corporal y espiritual que la Iglesia como institución ejerció y ejerce en México, 2033 logra articular una visión del futuro que responde bien al contexto mexicano y latinoamericano, en tanto no se limita a la absorción y reproducción de códigos hollywoodenses. Aun cuando mi propósito ha sido mostrar la crítica que 2033 lleva a cabo en relación a la tecnología como parte instrumental del proyecto modernizador de México en el neoliberalismo, es preciso mencionar que esta película deja muchas otras áreas del modelo neoliberal sin tocar. No interroga a fondo las cuestiones de clase (los pobres siguen siendo una masa indistinguible, los protagonistas forman parte de un grupo privilegiado o poseen puestos de autoridad dentro de su clase), ni tampoco dedica mucho tiempo en indagar acerca del proceso que sumió a México en el régimen dictatorial del año 2033.

No obstante estas fallas, hay que reconocer y tener presente que el cine de ciencia ficción mexicano actual es, ante todo, un género comercial, y que por ende uno de sus propósitos es circular en el mercado cinematográfico global. En este sentido, el hecho de ubicar espacialmente la película en México y abordar temas como la globalización, el neoliberalismo, los regímenes dictatoriales, la violencia y la represión, también puede ser visto como un intento por ubicarse dentro de una corriente de películas latinoamericanas que han tratado los mismos temas (Amores Perros, Ciudad de Dios), y así conseguir una mayor difusión.

Quizás sea demasiado apresurado especular sobre una posible estabilización del género en México, más aún cuando se toman en cuenta los resultados poco alentadores en términos económicos y críticos. Sin embargo, el interés por este cine parece continuar, por lo que un análisis detallado del corpus completo de la ciencia ficción mexicana podría ofrecer pistas del estado de la cinematografía nacional y también de las nuevas ansiedades de la clase hacia la que este género va dirigido.

${ }_{13}$ Sobre el papel que ha jugado la tecnología en el EZLN y otros movimientos similares consúltese el ensayo de Thea Pitmann "Latin American Cyberprotest: Before and After the Zapatistas." 


\section{BiBLIOGRAFÍA}

2033. Francisco Laresgoiti, dir. México DF: Fílmica Villaparaíso, 2009.

Caballero, Jorge. "2033 aborda el tema de una sociedad manipulada por un régimen militar, dice Francisco Laresgoiti”. La Jornada. 5 feb. 2010. <http://www.jornada. unam.mx/2010/02/05/espectaculos/a10n1esp>. 14 feb. 2013.

Fernández, Miguel Ángel. “Querida, convertí la pantalla en cobre. Del cine mexicano de ciencia ficción al bestiario de la mitología popular nacional, 1945-1981”. El futuro más acá: Cine mexicano de ciencia ficción. Itala Schmelz, ed. México, DF: Landucci, UNAM, CONACULTA, 2006. 131-149.

Galloway, Alexander R. y Eugene Thacker. The Exploit: a Theory of Networks. Minneapolis: U of Minnesota P, 2007.

Huerta, César. "2033: ¿El futuro de la Ciudad de México?”. El Universal. 30 marzo 2008. <http://www.eluniversal.com.mx/espectaculos/96724.html>. 13 feb. 2013. "Las cucarachas invaden el DF en la cinta 2033". El Universal. 30 marzo 2008. $<$ http://www.eluniversal.com.mx/espectaculos/96872/html>. 13 feb. 2013.

“Más de 100 mil vieron el filme 2033”. El Universal. 14 feb. 2010. <http:// www.eluniversal.com.mx/espectaculos/96872.html>. 13 feb. 2013.

Johnston, Keith M. Science Fiction Film: A Critical Introduction. Nueva York: Berg Publishers, 2011.

Juárez, Hugo. "Crítica / reseña 2033”. Psicodiarrea: videojuegos, cine, anime y demás vicios enajenantes. 8 feb. 2010. <http://psicodiarrea.blogspot.com/2010/02/ critica-resena-2033.html>.

López, Miguel. Utopian Dreams, Apocalyptic Nightmares: Globalization in Recent Mexican and Chicano Narrative. West Lafayette: Purdue UP, 2008.

MacLaird, Misha. Aesthetics and Politics in the Mexican Film Industry. Nueva York: Palgrave, 2013.

Meyer, Jean. La Cristiada. México DF: Fondo de Cultura Económica, 2007.

Paz, Mariano. "South of the Future: An Overview of Latin American Science Fiction Cinema." Science Fiction Film and Television I/1 (2008): 81-103. 14 feb. 2013.

Peredo Castro, Francisco. Cine y propaganda para Latinoamérica: México y Estados Unidos en la encrucijada de los años cuarenta. México DF: UNAM, Centro Coordinador y Difusor de Estudios Latinoamericanos, Centro de Investigaciones sobre América del Norte, 2004.

Pitman, Thea. "Latin American Cyberprotest: Before and After the Zapatistas." Latin American Cyberculture and Cyberliterature. Claire Taylor y Thea Pitman, eds. Liverpool: Liverpool UP, 2007. 86-110.

Rosas Mantecón, Ana. "Las batallas por la diversidad: exhibición y públicos de cine en México”. Situación actual y perspectivas de la industria cinematográfica en 
México y en el extranjero. Néstor García Canclini et al., coords. Guadalajara: Universidad de Guadalajara, IMCINE, 2006. 263-291.

Sánchez Prado, Ignacio. "Niñas Mal y la culminación del cine comercial en México". El Blog de Ignacio Sánchez Prado. 6 nov 2011. <http://ignaciosanchezprado. blogspot.com>. 15 feb. 2013.

Sobchack, Vivian. Screening Space: The American Science Fiction Film. Nueva York: Ungar, 1993.

Schmelz, Itala. El futuro más acá: cine mexicano de ciencia ficción. México DF: Landucci, UNAM, CONACULTA, 2006.

Yehya, Naief. "Del más allá al más acá”. Letras Libres. Abril (2005): 72-73.

Wilt, David. "Mexican Fantasy Films: A Brief History." Mexican Horror Cinema. Posters From Mexican Fantasy Films. Rogelio Agrasánchez, Jr., ed. Harlingen, TX: Agrasánchez Film Archive, 1999. 11-21.

Wolff, Gary K. Critical Terms for Science Fiction and Fantasy: A Glossary and Guide to Scholarship. Nueva York: Greenwood Press, 1986. 
